\title{
Ossifying fibroma in the maxilla and orbital floor: report of an uncommon case
}

\author{
Diogo de Vasconcelos Macedo, Gabriely Ferreira, Eduardo Hochuli Vieira, Marcelo Silva Monnazzi \\ Department of Diagnosis and Maxillofacial Surgery, São Paulo State University (UNESP) Dental School, Araraquara, Brazil
}

\begin{abstract}
J Korean Assoc Oral Maxillofac Surg 2020;46:204-207)
Benign fibro-osseous lesions occur when normal bone is replaced by cellular fibrous connective tissue and mineralized structures. One rare type of these lesions is the ossifying fibroma (OF). The aim of this study is to report an unusual case of OF in a 57-year-old female. Physical examination showed facial asymmetry without any tenderness, fluctuation, ocular pain, or ophthalmoplegia. Imaging exams revealed a solid mass involving the left maxilla and orbital floor. Surgical resection was performed without any complications or sequelae, and the histopathological results confirmed OF. Although recurrence is rare in this condition, the patient remains under follow-up.
\end{abstract}

Key words: Ossifying fibroma, Maxilla, Orbit

[paper submitted 2018. 7. 3 / revised 2018. 8. 20 / accepted 2018. 8. 22]

\section{Introduction}

Ossifying fibroma (OF) is classified as a rare, benign fibroosseous lesion that occurs most commonly in tooth-bearing areas, with a prevalence in the lower jaw up to $90 \%$ and a male to female ratio of $1: 5^{1}$. Clinically, OF usually presents as a painless, expansive, central mass that is discovered incidentally. However, some cases present with pain, paresthesia, nasal obstruction, aesthetic deformity, or orbital impairment ${ }^{2}$. Histologically, the lesions show replacement of normal bone by fibrous connective tissue with varying degrees of mineralization. Therefore, the definitive diagnosis requires a combined assessment of clinical, microscopic, and radiological features ${ }^{3}$.

The aim of this study is to report an unusual case of OF in a 57-year-old female whose lesion was localized in the left

\footnotetext{
Diogo de Vasconcelos Macedo

Department of Diagnosis and Maxillofacial Surgery, São Paulo State University (UNESP) Dental School, Humaitá Street, 1680, Araraquara, SP, CEP 14801-385, Brazil

TEL: +55-91-981552015 FAX: +55-16-3301-6300

E-mail:diogo.v.macedo@gmail.com

ORCID: https://orcid.org/0000-0002-8050-3534

(c) This is an open-access article distributed under the terms of the Creative Commons Attribution Non-Commercial License (http://creativecommons.org/ licenses/by-nc/4.0/), which permits unrestricted non-commercial use, distribution, and reproduction in any medium, provided the original work is properly cited.

Copyright (C) 2020 The Korean Association of Oral and Maxillofacial Surgeons. All rights reserved.
}

region of the maxilla and associated with impairment of the orbital floor and to discuss aspects of treatment.

\section{Case Report}

A 57-year-old female presented with a 14-month history of a painless swelling in the left maxilla. She reported no history of trauma or fever. Clinically, the patient had moderate facial asymmetry with attenuation of the nasolabial sulcus.(Fig. 1) Intraorally, a palpable, $3 \mathrm{~cm} \times 4 \mathrm{~cm}$, hard mass was present with normal color of the overlying mucosa and without dislocation of teeth from the alveolar ridge. No occlusal, temporomandibular joint, or neural disorders were present during the initial evaluation, and no tenderness or fluctuation was noted.

Computed tomography (CT), including axial, sagittal, and coronal slices, as well as three-dimensional reconstruction, showed a large and well-defined hypodense mass surrounded by a thin sclerotic rim in the left maxillary bone that involved three molars and extended to the orbital floor and zygomatic bone.(Fig. 2) An incisional biopsy was performed, and the histopathological analysis was compatible with OF.

The goals following surgical planning consisted of conservative tumor excision and evaluation of the orbital floor to assess the need of reconstruction during the procedure. A circumvestibular incision in combination with a subciliar access was performed to achieve adequate visualization of the 
tumoral mass and bone margins. The tumor presented as a large fibrous mass with well-defined margins and was easily detachable from the adjacent bone, but it fully surrounded the infraorbital nerve and partially surrounded the inferior rectus muscle (IRM). Therefore, great attention was given to preservation of these structures during excision, and total removal was successfully carried out.(Fig. 3) A $5 \mathrm{~mm} \times 4 \mathrm{~mm}$ defect was present in the left orbital floor, but it was limited to the anterior portion, and no reconstruction was carried out. Ocular motility was assessed to ensure preservation of muscular activity. Due to complete destruction of the surrounding bone, a $2.0 \mathrm{~mm}$ trauma plate was used to reestablish the zygomatic buttress.

Histopathological examination revealed areas of mature bone and a lesion composed of cellular fibrous tissue rich in fibroblasts and collagen fibers.(Fig. 4) Microscopic evaluation, combined with the clinical and radiographic findings,

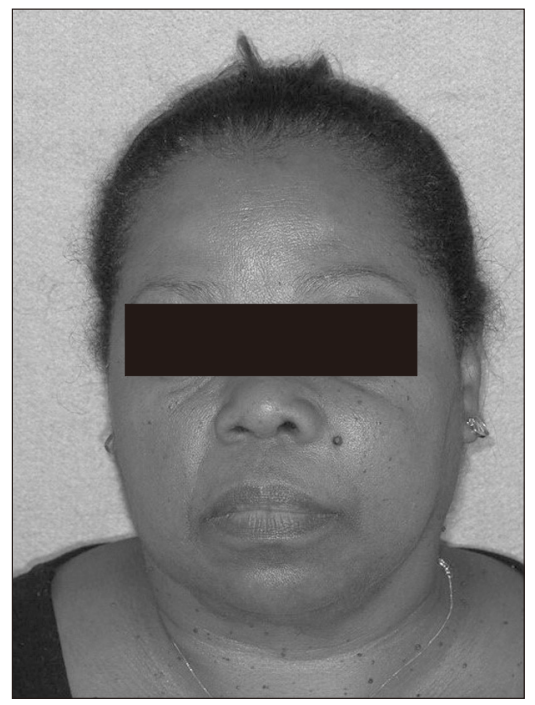

Fig. 1. Preoperatory clinical aspect.

Diogo de Vasconcelos Macedo et al: Ossifying fibroma in the maxilla and orbital floor: report of an uncommon case. J Korean Assoc Oral Maxillofac Surg 2020 confirmed the diagnosis of OF. Therefore, no further immunohistochemical analysis was performed. Fifteen days postoperatively, panoramic radiographs and CT imaging confirmed complete resection of the tumor. The patient was observed in long-term follow-up, and after 50 months, no clinical or radiographic evidence of recurrence has been noted.(Fig. 5) In addition, no signs of orbital impairment developed. The patient is still being followed for periodic clinical and radiographic follow-up.

\section{Discussion}

OF is defined as a well demarcated lesion composed of fibro-cellular tissue and mineralized material of varying appearances. Several reclassifications have been made regarding fibro-osseous lesions of the jaw, which can make the terminology unclear. In the latest World Health Organization

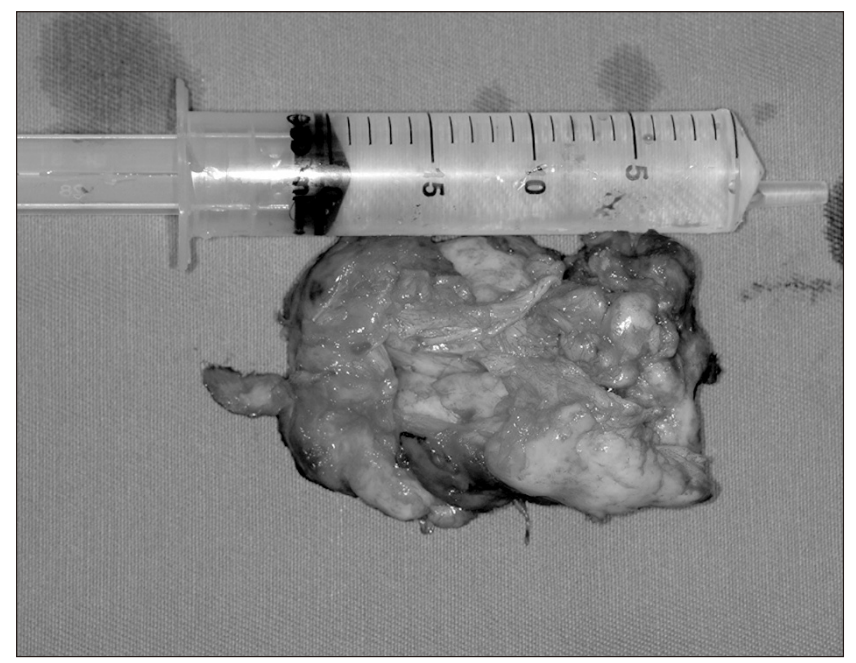

Fig. 3. Complete surgical excision of the specimen.

Diogo de Vasconcelos Macedo et al: Ossifying fibroma in the maxilla and orbital floor: report of an uncommon case. J Korean Assoc Oral Maxillofac Surg 2020

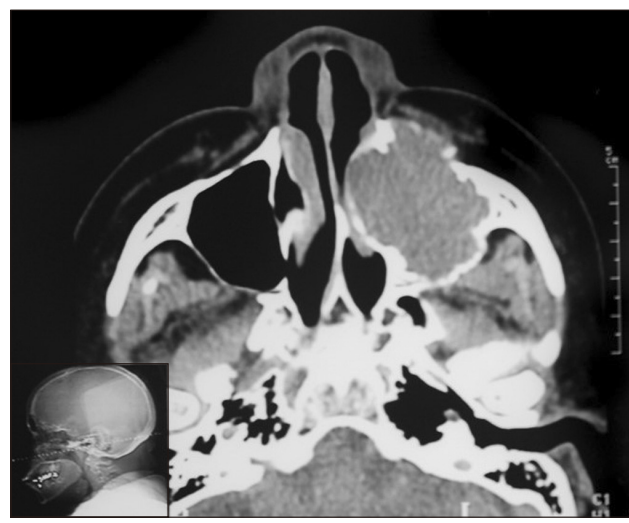

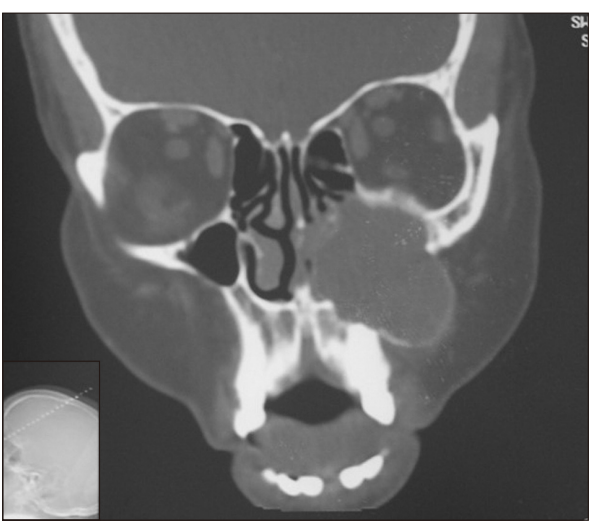

Fig. 2. Computed tomography scan showing large tumoral mass.

Diogo de Vasconcelos Macedo et al: Ossifying fibroma in the maxilla and orbital floor: report of an uncommon case. J Korean Assoc Oral Maxillofac Surg 2020 


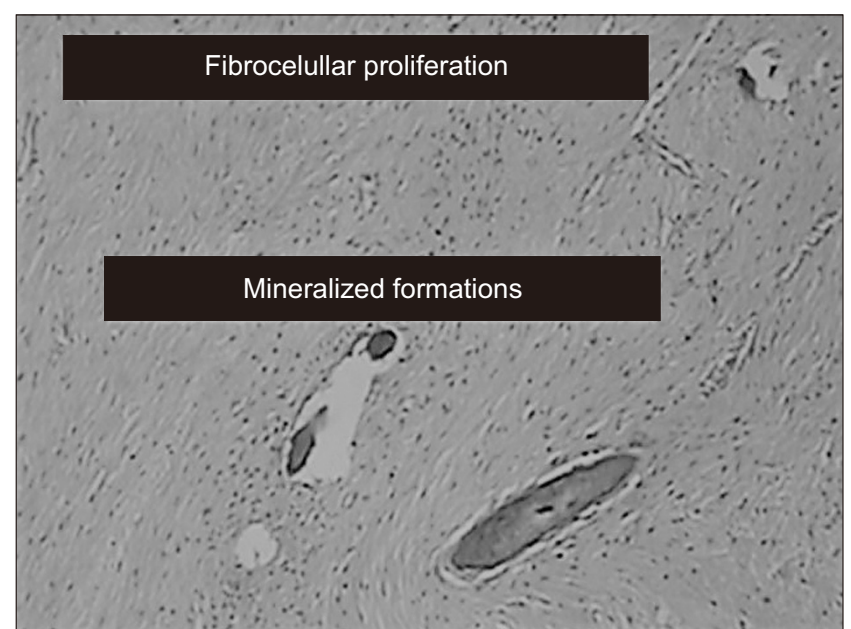

Fig. 4. Histopathological analysis compatible with ossifying fibroma (H\&E staining, $\times 20$ ).

Diogo de Vasconcelos Macedo et al: Ossifying fibroma in the maxilla and orbital floor: report of an uncommon case. J Korean Assoc Oral Maxillofac Surg 2020

classification, the term "ossifying fibroma" comprises three distinct entities: conventional OF, juvenile trabecular OF, and juvenile psammomatoid OF, with the juvenile patterns showing more aggressive behavior ${ }^{4}$.

Lesions most commonly occur in patients' second to fourth decade, with a striking predilection for females (1:5). The lesions are usually asymptomatic, although patients may report pain or paresthesia ${ }^{3,4}$. Although the patient in the present case was in the sixth decade of life, the main characteristics of OF were present. Differential diagnosis of such pathology may be challenging for the clinician due to a large variety of histological features and a significant overlap between them. Furthermore, radiological and clinical findings may be confused with other fibro-osseous lesions ${ }^{5,6}$. In histological analysis, OFs are composed of a fibrous component with variable cellularity. The mineralized portion may be formed by woven bone, lamellar bone, or a mineralized component with either few cells or acellular, commonly classified as cementum ${ }^{7,8}$. Commonly, OFs are confused with fibrous dysplasia in the microscopic analysis due to its similar variations in stromal cellularity and occurrence of mineralized material, which highlights the need for clinicians to correlate clinical and radiographic findings with histological analysis ${ }^{8,9}$. The histopathological analysis of the specimen in the present case revealed areas of mature bone surrounded by a highly cellular fibrous tissue rich in fibroblasts and collagen fibers without cellular atypia.

The treatment choice for OF must consider the size of the mass, degree of bone invasion, circumjacent structures, and

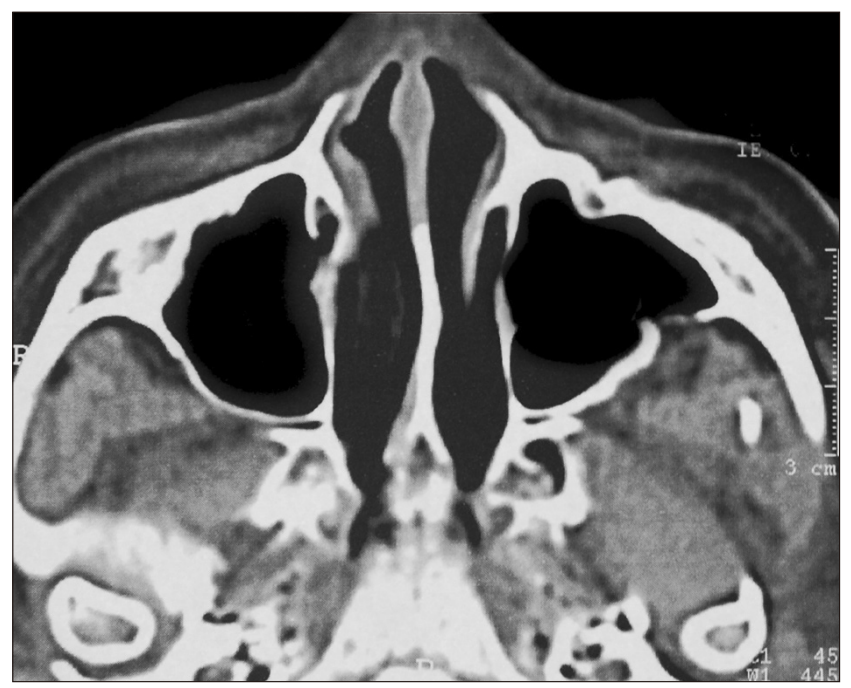

Fig. 5. Postoperative computed tomography scan showing complete tumour excision.

Diogo de Vasconcelos Macedo et al: Ossifying fibroma in the maxilla and orbital floor: report of an uncommon case. J Korean Assoc Oral Maxillofac Surg 2020

involvement of surrounding soft tissues. The surgical approach may vary from enucleation with curettage to resection with a small margin, depending on the characteristics of the lesion. Complete removal of maxillary OFs may be more challenging than those of other locations due to the characteristics of the maxillary bone, the available space for expansion into the maxillary antrum, and possible invasion of the nasal and/or orbital cavities ${ }^{2,10}$. Recurrences are uncommon, even with enucleation and curettage only, though some authors have advised long-term follow-up of such affected patients ${ }^{1,6}$.

The present case was treated with conservative surgical enucleation due to the clear distinction between the lesion and healthy bone and the rare possibility of recurrence. Exploration of the orbital floor was performed through a subciliar approach, which allowed wide exposure, adequate removal of the orbital portion of the tumor, and dissection of IRM, which was involved in the tumoral mass. After excision, the orbital floor was fully evaluated. A round $5 \mathrm{~mm} \times 4 \mathrm{~mm}$ defect that was limited to the anterior portion of the orbit was present without involvement of the medial wall. No reconstruction was carried out, and ocular motility was assessed. No enophthalmos or diplopia was observed in the long-term follow-up.

The surgical planning for the present case was based on the location of the mass in the maxilla with involvement of the orbit and zygomatic bone, as well as the rarely reported recurrence of such large maxillary lesions.

In conclusion, $\mathrm{OF}$ in the maxillofacial skeleton, as presented in this report, is uncommon, and differential diagnosis can 
be confusing. Furthermore, the possible differential diagnoses highlights the need to correlate the clinical, radiological, and microscopic examinations to establish adequate treatment protocols.

\section{ORCID}

Diogo de Vasconcelos Macedo, https://orcid.org/00000002-8050-3534

Gabriely Ferreira, https://orcid.org/0000-0002-4102-0038

Eduardo Hochuli Vieira, https://orcid.org/0000-0003-40409313

Marcelo Silva Monnazzi, https://orcid.org/0000-0001$6142-4630$

\section{Authors' Contributions}

D.V.M. and G.F. participated in data collection and wrote the manuscript. E.H.V. and M.S.M. were responsible for surgical procedure.

\section{Consent for Publishing Photographs}

Written informed consent was obtained from the patient for publication of this article and accompanying images.

\section{Conflict of Interest}

No potential conflict of interest relevant to this article was reported.

\section{References}

1. Eversole LR, Leider AS, Nelson K. Ossifying fibroma: a clinicopathologic study of sixty-four cases. Oral Surg Oral Med Oral Pathol 1985;60:505-11.

2. Gondivkar SM, Gadbail AR, Chole R, Parikh RV, Balsaraf S. Ossifying fibroma of the jaws: report of two cases and literature review. Oral Oncol 2011;47:804-9.

3. Eversole R, Su L, ElMofty S. Benign fibro-osseous lesions of the craniofacial complex. A review. Head Neck Pathol 2008;2:177202.

4. Barnes L, Eveson JW, Reichart P, Sidransky D. Pathology and genetics of head and neck tumours. World Health Organization classification of tumours. Lyon: IARC Press; 2005:163-75.

5. Mohanty S, Gupta S, Kumar P, Sriram K, Gulati U. Retrospective analysis of ossifying fibroma of jaw bones over a period of 10 years with literature review. J Maxillofac Oral Surg 2014;13:560-7.

6. Liu Y, Wang H, You M, Yang Z, Miao J, Shimizutani K, et al. Ossifying fibromas of the jaw bone: 20 cases. Dentomaxillofac Radiol 2010;39:57-63.

7. Brannon RB, Fowler CB. Benign fibro-osseous lesions: a review of current concepts. Adv Anat Pathol 2001;8:126-43.

8. Slootweg PJ. Maxillofacial fibro-osseous lesions: classification and differential diagnosis. Semin Diagn Pathol 1996;13:104-12.

9. Voytek TM, Ro JY, Edeiken J, Ayala AG. Fibrous dysplasia and cemento-ossifying fibroma. A histologic spectrum. Am J Surg Pathol 1995; 19:775-81

10. Zegalie N, Speight PM, Martin L. Ossifying fibromas of the jaws and craniofacial bones. Diagn Histopathol 2015;21:351-8.

How to cite this article: de Vasconcelos Macedo D, Ferreira G, Vieira EH, Monnazzi MS. Ossifying fibroma in the maxilla and orbital floor: report of an uncommon case. J Korean Assoc Oral Maxillofac Surg 2020;46:204-207. https://doi.org/10.5125/jkaoms.2020.46.3.204 